msh-mss Mathématiques et sciences humaines

134 | Été 1996

Varia

\title{
Les statistiques de police : méthodes de production et condition d'interprétation
}

Criminal Investigation Department data : methods of production and conditions of interpretation

Bruno Aubusson De Cavarlay

\section{OpenEdition}

Journals

Édition électronique

URL : http://journals.openedition.org/msh/2728

DOI : $10.4000 / \mathrm{msh} .2728$

ISSN : 1950-6821

Éditeur

Centre d'analyse et de mathématique sociales de l'EHESS

Édition imprimée

Date de publication : 1 mars 1996

ISSN : 0987-6936

Référence électronique

Bruno Aubusson De Cavarlay, «Les statistiques de police : méthodes de production et condition

d'interprétation », Mathématiques et sciences humaines [En ligne], 134 | Été 1996, mis en ligne le 10

février 2006, consulté le 23 juillet 2020. URL : http://journals.openedition.org/msh/2728 ; DOI : https:// doi.org/10.4000/msh.2728

Ce document a été généré automatiquement le 23 juillet 2020

(c) École des hautes études en sciences sociales 


\section{Les statistiques de police : méthodes de production et condition d'interprétation}

Criminal Investigation Department data : methods of production and conditions of interpretation

Bruno Aubusson De Cavarlay

\section{RÉSUMÉS}

Dans cet article, l'auteur mène une critique approfondie des données statistiques concernant la police judiciaire. L'étude concerne surtout des questions méthodologiques.

In this paper, the author examine statistical data about Criminal Investigation Department with a critical eye. He studies principally methodological problems.

INDEX

Thèmes : données (analyse des), méthodologie, sociologie, statistique 